Original Article

\title{
An observational study on breast feeding Success among postnatal mothers
}

\author{
Sabitha Nayak \\ Vice Principal, Nitte Usha Institute of Nursing Sciences, Nitte University, M angalore. \\ Correspondence \\ Sabitha Nayak \\ Vice Principal, Nitte Usha Institute of Nursing Sciences, Nitte University, Mangalore. \\ M obile : +919448842698 E-mail : sabitha@ nitte.edu.in
}

\begin{abstract}
Background : Under modern health care, human breast milk is considered the healthiest form of milk for babies. It also promotes the health of both mother and infant and helpsto prevent disease. ${ }^{1}$

WHO states that, the vast majority of mothers can and should breast feed, just as the vast majority of infants can and should be breast fed. ${ }^{5}$

Purpose : The current study has aimed to determine the breastfeeding success among postnatal mothers.

Methods : A descriptive survey approach was conducted on 50 postnatal mothers who were in the postnatal wards of a selected hospital. Observational checklist with 26 items were utilized to collect data.

Results : Through descriptive analysis it was found that majority (44\%) of mothers were in the age group of 20 - 25 years. M ajority (68\%) were Hindus. In type of delivery $84 \%$ had full term normal delivery. With regards to parity, $44 \%$ were multis. In relation to sex of the baby, $68 \%$ were females. The condition of the mother and the baby after delivery was good and normal in $100 \%$. An observational checklist on breastfeeding success shows that the success rate on breastfeeding was high. There were 4 items such as getting ready to feed, Latching on, Feed itself and after feed and each item had 4 to 8 specific items on observational checklists on breastfeeding which indicates that in most of the mothers breastfeeding was a success. By inferential statistics it was found that type of delivery is associated with breast feeding $(P<0.05)$. Since all other $p$ values are more than 0.05 there was no association between those selected demographic variables with breast feeding at $5 \%$ level of significance.

Conclusion : Breast feeding is an age-old practice among most of the post-natal mothers to feed their young ones. In India, most of the mothers, practice giving breast milk to babies for about 1 to 2 years. Assistance by the health workers is not much sought as most of the bystanders assist the mothers in breast feeding. In the present study also, we have come across mothers successfully breastfeeding their babies and they are contented.
\end{abstract}

Keywords: Breastfeeding, Postnatal mothers.

\section{Introduction}

Breast feeding was the common practice since ancient times and it is practiced even today. With the $18^{\text {th }}$ and $19^{\text {th }}$ century industrialisation in the Western world, working mothers in many urban centres began dispensing Breast feeding due to their work Access this article online Quick Response Code

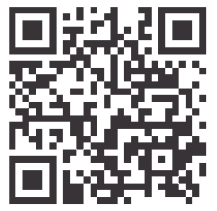
requirements. Under modern health care, human breast milk is considered the healthiest form of milk for babies. It also promotes the health of both mother and infant and helpsto prevent disease. . $^{1,2,3,4}$

WHO states that, the vast majority of mothers can and should breast feed, just as the vast majority of infants can and should be breast fed. Only under exceptional circumstances can a mother's milk be considered unsuitable for her infant. WHO also recommends exclusive Breast feeding for the first six months of life.AAP (American Academy of Paediatrics) recommends exclusive breast feeding for the first six months of life and it should be continued for at least the First year of life and beyond for as long as mutually desired by mother and child. ${ }^{5,6}$

WHO also states that Breast feeding is the normal way of 
providing young infants with the nutrients they need for healthy growth and development. Virtually all mothers can Breast feed, provided they have accurate information and the support of their family. The health care system and society at large. Colostrum, the yellowish sticky Breast milk produced at the end of pregnancy, is recommended by WHO as the perfect food for the newborn. ${ }^{7}$ and all mothers should be inculcated to practice giving first feed (colostrum) to the infant

Statement of the problem: An Observational study on breastfeeding success among postnatal mothers in Justice K.S. Hegde Hospital, Mangalore, India.

\section{Objectives}

1. To determine the breast feeding success among postnatal mothers

2. To find an association on breast feeding success with selected demographic variables

\section{Methods}

A descriptive survey was carried out in a selected postnatal unit of a hospital in M angalore. 50 postnatal mothers who were breast feeding were selected by convenient sampling. Consent was taken from each of the participants who were willing to participate in the study. Two tools were used for data collection.

Tool 1: Sample characteristics.

Tool 2: Observational checklist on breastfeeding.

\section{Results}

Through descriptive analysis it was found that majority (44\%) of mothers were in the age group of 20 - 25 years. Majority (68\%) were Hindus. In type of delivery $84 \%$ had full term normal delivery. With regards to parity, $44 \%$ were multis. In relation to sex of the baby, $68 \%$ were females. The condition of the mother and the baby after delivery was good and normal in 100\% [Table 1]. An observational checklist on breastfeeding success shows that the success rate on breastfeeding was high. There were 4 items such as getting ready to feed, Latching on, Feed itself and after feed and each item had 4 to 8 specific items on observational checklists on breastfeeding which indicates that in most of the mothers breastfeeding was a success [Table 2]. By inferential statistics it was found that type of delivery is associated with breast feeding $(P<0.05)$. Since all other $p$ values are more than 0.05 there was no association between those selected demographic variables with breast feeding at $5 \%$ level of significance [Table3].

Distribution of sample according to the demographic characteristics

$n=50$

\begin{tabular}{|l|l|c|c|}
\hline SI.No. & Demographic Variables & Frequency $(\mathrm{f})$ & Percentage (\%) \\
\hline 1. & Age in years & & \\
\hline 1.1 & $20-25$ & 22 & $44 \%$ \\
\hline 1.2 & $26-30$ & 18 & $36 \%$ \\
\hline 1.3 & $31-35$ & 6 & $12 \%$ \\
\hline 1.4 & $36-40$ & 4 & $8 \%$ \\
\hline 2. & Religion & & \\
\hline 2.1 & Hindu & 34 & $68 \%$ \\
\hline 2.2 & Christian & 2 & $4 \%$ \\
\hline 2.3 & M uslim & 14 & $28 \%$ \\
\hline 3. & Type of delivery & & \\
\hline 3.1 & FTND & 52 & $84 \%$ \\
\hline 3.2 & LSCS & 3 & 10 \\
\hline 3.3 & Instrumental & & $6 \%$ \\
\hline 4. & Parity & 19 & 38 \\
\hline 4.1 & Primi & 22 & 44 \\
\hline 4.2 & Multi & 9 & 18 \\
\hline 4.3 & M ore than 2 & & \\
\hline
\end{tabular}


Observational check-list Breast-feeding

$\mathrm{n}=\mathbf{5 0}$

\begin{tabular}{|c|c|c|c|c|c|}
\hline SNo. & Assessment tool & Yes & $\%$ & No & $\%$ \\
\hline & \multicolumn{5}{|l|}{ Getting ready to feed } \\
\hline 1. & Mother is relaxed and comfortable & 47 & 94 & 3 & 6 \\
\hline 2. & Breast is not restricted by clothing & 44 & 88 & 6 & 12 \\
\hline 3. & Breast full, soft and rounded, no skin redness & 45 & 90 & 5 & 10 \\
\hline 4. & Nipples prominent, not cracked or bruised & 42 & 84 & 8 & 16 \\
\hline \multicolumn{6}{|c|}{ Latching on } \\
\hline 5. & Baby reaches for the breast, roots opens wide & 47 & 94 & 3 & 6 \\
\hline 6. & Tongue movement explores the breasts. & 44 & 88 & 6 & 12 \\
\hline 7. & Baby's body is in a straight line & 45 & 90 & 5 & 10 \\
\hline 8. & Baby comes to the breast, chin and bottom lip first. & 42 & 84 & 8 & 16 \\
\hline 9. & Upper lip opposite the nipple before latching on & 46 & 92 & 4 & 8 \\
\hline 10. & There may be signs of milk release & 43 & 86 & 7 & 14 \\
\hline \multicolumn{6}{|c|}{ The feed itself } \\
\hline 11. & The baby is held securely, with touching and eye contact from mother & 48 & 96 & 2 & 4 \\
\hline 12. & Baby is held close to mother's body, whole body supported, not just head or shoulders & 44 & 88 & 6 & 12 \\
\hline 13. & Head slightly extended, chin touching breast & 45 & 90 & 5 & 10 \\
\hline 14. & Baby stays attached, does not slip off & 39 & 78 & 11 & 22 \\
\hline 15. & Calm and alert, though eyes may close towards end of feed & 49 & 98 & 1 & 2 \\
\hline 16. & Lower lip curled out & 41 & 82 & 9 & 18 \\
\hline 17. & If visible, more areola above the baby's top lip & 43 & 86 & 7 & 14 \\
\hline 18. & Cheeks rounded, not sucked in, no clicking sounds & 44 & 88 & 6 & 12 \\
\hline 19. & Slow deep sucks, bursts with pauses & 48 & 96 & 2 & 4 \\
\hline 20. & Rhythmic swallowing seen and heard & 46 & 92 & 4 & 8 \\
\hline 21. & Baby releases breast spontaneously at end of feed & 43 & 86 & 7 & 14 \\
\hline \multicolumn{6}{|c|}{ After the feed } \\
\hline 22. & Evidence of milk transfer - milk iin the baby's mouth and around the nipple & 42 & 84 & 8 & 16 \\
\hline 23. & Nipple undamaged, normal shape and colour & 48 & 96 & 2 & 4 \\
\hline 24. & Areola - no bruising or compression marks & 41 & 82 & 9 & 18 \\
\hline 25. & Breast softer & 46 & 92 & 4 & 8 \\
\hline 26. & Contented baby & 45 & 90 & 5 & 10 \\
\hline
\end{tabular}

In the above table, there were 4 items, and each item had 4 to 8 specific items on observational checklists on breastfeeding which indicates that in most of the mothers breastfeeding was a success.

Fisher's Exact Test computed to determine the significance of association on breastfeeding and selected demographic variables

\begin{tabular}{|c|c|c|c|c|c|}
\hline \multicolumn{2}{|c|}{ Selected demographic variables } & \multicolumn{2}{|c|}{ Checklist score categorized } & \multirow{2}{*}{$\begin{array}{c}\text { Fishers Exact } \\
\text { test }\end{array}$} & \multirow[t]{2}{*}{$P$ value } \\
\hline & & $<$ M edian (23) & $>$ M edian (23) & & \\
\hline \multirow[t]{4}{*}{ Age } & $20-25$ & 10 & 12 & \multirow[t]{4}{*}{4.488} & \multirow[t]{4}{*}{$0.227 \mathrm{NS}$} \\
\hline & $26-30$ & 7 & 11 & & \\
\hline & $31-35$ & 5 & 1 & & \\
\hline & $36-40$ & 3 & 1 & & \\
\hline \multirow[t]{3}{*}{ Religion } & Hindu & 18 & 16 & \multirow[t]{3}{*}{2.861} & \multirow[t]{3}{*}{$0.228 \mathrm{NS}$} \\
\hline & Christian & 2 & 0 & & \\
\hline & Muslim & 5 & 9 & & \\
\hline \multirow[t]{3}{*}{ Type of delivery } & Full time normal delivery & 17 & 25 & \multirow[t]{3}{*}{8.978} & \multirow[t]{3}{*}{$0.004 * \mathrm{~S}$} \\
\hline & LSCS & 5 & 0 & & \\
\hline & Instrumental & 3 & 0 & & \\
\hline \multirow[t]{3}{*}{ Parity } & Primi & 9 & 10 & \multirow[t]{3}{*}{1.229} & \multirow[t]{3}{*}{$0.654 \mathrm{NS}$} \\
\hline & Multi & 10 & 12 & & \\
\hline & More than 2 & 6 & 3 & & \\
\hline
\end{tabular}




\begin{tabular}{|c|c|c|c|c|c|}
\hline \multicolumn{2}{|c|}{ Selected demographic variables } & \multicolumn{2}{|c|}{ Checklist score categorized } & \multirow{2}{*}{$\begin{array}{c}\text { Fishers Exact } \\
\text { test }\end{array}$} & \multirow[t]{2}{*}{$P$ value } \\
\hline & & $<$ M edian (23) & $>$ M edian (23) & & \\
\hline \multirow[t]{2}{*}{ Sex of the baby } & Male & 4 & 10 & \multirow[t]{2}{*}{0.043} & \multirow[t]{2}{*}{$0.069 \mathrm{NS}$} \\
\hline & Female & 20 & 14 & & \\
\hline \multirow[t]{2}{*}{ Weight of the baby } & Less than 2.5 & 6 & 2 & \multirow[t]{2}{*}{0.099} & \multirow[t]{2}{*}{$0.247 \mathrm{NS}$} \\
\hline & More than 2.5 & 19 & 23 & & \\
\hline \multirow[t]{5}{*}{ Period of gestation } & Less than or equal to 37 & 1 & 4 & \multirow[t]{5}{*}{3.173} & \multirow[t]{5}{*}{$0.585 \mathrm{NS}$} \\
\hline & 38 & 14 & 11 & & \\
\hline & 39 & 3 & 5 & & \\
\hline & 40 & 6 & 4 & & \\
\hline & More than 40 & 1 & 1 & & \\
\hline \multirow[t]{3}{*}{ Educational status } & 5 to 7 & 1 & 1 & \multirow[t]{3}{*}{5.526} & \multirow[t]{3}{*}{$0.049 \mathrm{NS}$} \\
\hline & 8 to 10 & 7 & 1 & & \\
\hline & PUC and above & 17 & 23 & & \\
\hline
\end{tabular}

* Indicate significant

The above shows that, type of delivery is associated with breast feeding $(P<0.05)$. Since all other $P$ values are more than 0.05 there is no association between those selected demographic variables with breast feeding at $5 \%$ level of significance.

\section{A similar study on KAP STUDY OF FACTORS PROMOTING} BREASTFEEDING IN NURSING MOTHERS AND PREGNANT WOMEN was conducted at a tertiary teaching hospital of coastal south India on 300 subjects and the results were $36 \%$ had primary education and $12 \%$ were graduates. Majority (61\%) lived in a joint family. Only $52.3 \%$ of the subjects received advice on breastfeeding during antenatal visits, out of which only $19.3 \%$ had a breast examination. $58.7 \%$ knew that breastfeeding should be initiated within 1 hour of child birth but only $48 \%$ of the mothers who had delivered initiated breastfeeding within 1 hour. $71.6 \%$ of the mothers knew that exclusive breastfeeding should be practised for 6 months. On univariate analysis mothers with more than 1 child, vaginal delivery and an educated partner had awareness of breastfeeding and practiced healthy breastfeeding and this study emphasises the need to counsel mothers regarding breastfeeding practices early during antenatal visits and not postpone till after delivery, include the spouse for support, sensitise the health care giver and improve infrastructure for a successful breastfeeding initiation. ${ }^{16}$

A study on 'Pain and breastfeeding: a prospective observational study' was conducted on seventy-nine patients regarding satisfaction in breastfeeding, tiredness, uterine pain, nipple and other pain, and analgesic use at day three and at first, second, third, and fourth week after birth. Data regarding the mode of delivery were recorded from medical charts. Milk formula supplements, bottle use, pacifier use, and nipple shields use were considered as variables suggesting unsuccessful breastfeeding. And the results were at the third day after delivery, it appeared that analgesic use was significantly associated with milk formula supplementing, bottle use, less satisfaction in breastfeeding, and more tiredness. At first week after delivery, the presence of pain differing from nipple and uterine pain was more likely associated with milk formula supplementing, bottle use, pacifier use, less satisfaction in breastfeeding, and more tiredness. At third week after delivery, nipple pain was directly related to tiredness, while it increased the odds of adding milk formula and using a bottle. $^{17}$

A retrospective study of 1893 mothers on 'Determinants of successful breastfeeding initiation in healthy term singletons: a Swiss university hospital observational study.' The results indicated multiparity was associated with nursing exclusively at the breast at discharge $(P \varangle 0.001)$, less use of maltodextrin supplement $(P \varangle 0.05)$, bottle/cup (both $P \varangle 0.001$ ), but more pacifier use $(P<0.05)$. Among obese mothers, nursing exclusively at the breast at discharge was less frequent, and use of all feeding aids more frequent, than among normal-weight women (both 
$P<0.001$ ). Neuraxial anesthesia was associated with use of maltodextrin and bottle (both $\mathrm{P} \varangle 0.05$ ) compared to no anesthesia. Delayed first skin-to-skin contact and roomingin for $<4 \mathrm{~h} /$ day were each associated with maltodextrin and cup ( $P \varangle 0.05$ ). Nursing exclusively at the breast at discharge was less frequent $(P \varangle 0.001)$, and bottle use more frequent $(P \varangle 05)$, in women with sore nipples than in those without. ${ }^{18}$

\section{A study on 'The effectiveness of a hospital-based program}

to promote exclusive breast-feeding among low-income

women in Brazil.' Was conducted with an active breastfeeding promotion program $(n=236)$ were compared with women who delivered at a nearby control hospital $(n=206)$ and the results showed that the two groups had similar

\section{Refferences :}

1. Picciano MF; "Nutrient composition of human milk". Pediatr.cin; February 2001; North America. 48 (1): 53 - 67.

2. Riordan JM (June 1997). "The cost of not breastfeeding: a commentary". J Hum Lact 13 (2): 93-7. doi:10.1177/ 089033449701300202 . PM ID 9233193.

3. Bartick M, Reinhold A (May 2010). "The burden of suboptimal breastfeeding in the United States: a pediatric cost analysis". Pediatrics 125 (5): e1048-56. doi:10.1542/peds.2009-1616. PMID 20368314. "If $90 \%$ of US families could comply with medical recommendations to breastfeed exclusively for 6 months, the United States would save $\$ 13$ billion per year and prevent an excess 911 deaths"

4. Falco M (2010-04-05). "Study: lack of breastfeeding costs lives, billions of dollars". CNN

5. WHO (2003). Global strategy for infant and young child feeding. Geneva, Switzerland.

6. Gartner LM, Morton J, Lawrence RA, et al. (February 2005) "Breastfeeding and the use of human milk". Pediatrics 115 (2): 496-506. doi:10.1542/peds.2004-2491

7. www.who.int/topics/BF/en

8. Tracking Progress on child and maternal mal nutrition; a survival and development priority UNICEF November 2009.

9. www.worldbreastfeedingtrends.org/report/WBTi-India.2012.pdf

10. Dyson.L, Mc Cormick F, Renfrew M.Interventions for promoting the initiation of Breastfeeding. Cochrane Database of systematic reviews 2005; 2:CD001688

11. Imdad A, Yakoob MY, Bhutta ZA. Effect of Breastfeeding promotion interventions on breastfeeding rates, with special focus on developing countries. BM C public health; 2011. demographic characteristics and previous breast-feeding histories. Exposure to breast-feeding activities, assessed by maternal recall prior to discharge, was universally high at the program hospital and universally low at the control hospital. Multivariate survival analysis showed that exclusive breast-feeding lasted 53 days longer among women who delivered at the program hospital. ${ }^{19}$

\section{Conclusion}

M DG-4 aims to reduce less than five child mortality by $2 / 3^{\text {rd }}$ by 2015. The UN secretary Generals global strategy for women's and Children's Health, 2012 has set a specific target for increase in $\mathbf{2 1 . 9}$ million infants who are exclusively breastfed for the first six months of life, by 2015 , in 49 developed countries. ${ }^{8}$

12. Victoria CG, Smith PG, Vaughan JP, Nobre LC, Lombardi C, Teixeira AM et al. Evidence for protection against infant deaths from infectious diseases in Brazil. Lancet 1987;2:319-322

13. Syed E Mahmood, Anurag Srivastava, Ved P Shrotriya, Payal M ishra, Infant feeding practices in the rural population of North India, Journal of Family and Community Medicine Official publication of the Saud Society of Family and Community M edicine , 2012; Vol. 19, Issue 2, Pg $130-135$

14. KM adhu, Chowdary Sri Ram, M asthi Ramesh, 'Breastfeeding practices and newborn care in rural areas'. Indian Journal of community medicine, July 2009; 34(3):243 - 246.

15. Kumar Dinesh, Agarwal Neeraj, Swami HM, 'Socio demographic correlates of breastfeeding in urban slums of Chandigarh', Indian Journal of M edical Sciences, 2006; Vol.60 Issue 11, Pg. 461 - 66.

16. Sharanya B. Shetty $\&$ Sudarshan Shetty K 'KAP STUDY OF FACTORS PROM OTING BREASTFEEDING IN NURSING MOTHERS AND PREGNANT WOM EN', NUJHSVol. 3, No.3, September 2013.

17. Indraccolo $U$, Bracalente $M$, i lorio $R$, Indraccolo SR, 'Pain and breastfeeding: a prospective observational study'Clinical and Experimental Obstetrics \& Gynecology [2012, 39(4):454-457]

18. Gubler $\mathrm{T}^{1}$, Krähenmann F, Roos M , Zimmermann R, Ochsenbein-Kölble $\mathrm{N}$. 'Determinants of successful breastfeeding initiation in healthy term singletons: a Swiss university hospital observational study' J Perinat Med. 2013 M ay; 41(3):331-9.

19. C K Lutter, R Perez-Escamilla, A Segall, T Sanghvi, K Teruya, and C Wickham. The effectiveness of a hospital-based program to promote exclusive breast-feeding among low-income women in Brazil. American Journal of Public Health April 1997: Vol. 87, No. 4, pp. 659663. 